\title{
STUDY THE EFFECT OF VARIOUS QUENCHING MEDIA ON HARDENING BEHAVIOR OF EN 9 STEEL
}

\author{
Mr. Bhavesh R. Rana \\ Technical Officer, Technology \\ Group, Theis Precision steel \\ India Pvt. Ltd., Navsari, \\ Gujarat, India
}

\author{
Mr. Kamlesh M. Rana \\ Assistant Manager (QA/QC), \\ AMNS India Limited, Hazira, \\ Surat, Gujarat, India
}

\author{
Dr. Vandana J. Rao \\ Associate Professor, Metallurgy and Material \\ Science Department, The Maharaja Sayajirao \\ University Of Baroda, Vadodara, Gujarat, \\ India
}

\begin{abstract}
Present investigation aims to determine the effect of quenching media like Water, Veg. oil, Industrial oil, Brine, Rolling mill coolant, Hybrid polymer solution) on hardening behavior of EN 9 steel. EN 9 steel is also designated as C55 DIN, AISI 1055 and SAE 1055. It is mainly consist of $\mathrm{C}(0.54 \%), \mathrm{Mn}(0.73 \%), \mathrm{Si}(0.21 \%), \mathrm{S} \& \mathrm{P}$ $(0.015 \%$ max.). EN 9 is widely use in automobile sector as clutch plates, Break Parts, agricultural equipment \& sometimes use as a structural engineering material. Different quenching media offers different type of micro structure. Normal quenching media used in industries are water, brine, oil etc. present research work involves the idea to optimization of mechanical/metallurgical properties of EN 9 steel by altering the quenching media. To consider effect of both conventional and non-conventional quenching media, present study involves use of water, brine, and industrial oil as conventional quenching media \& vegetable oil, rolling mill coolant emulsion and polymer solution as non-conventional quenching media. By altering quenching media microstructural changes occurs which directly affect the mechanical properties of EN 9 steel. Normally martensite, retained austenite $\&$ ferrite; their amount and location can control the hardness, tensile strength, yield strength and ductility of EN 9 steel. Brine solution offers best mechanical properties among all the other quenchants. Brine solution effect reflects in the form of lath martensite plates and retained austenite plus ferrite phase in the microstructure.
\end{abstract}

Keywords- Quenchants, polymer solution, Brine, Rolling mill coolant, Retain Austenite, Microstructure

\section{INTRODUCTION}

Steel is the most important engineering material in today's world. It is being used in almost every aspect of our lives; ranging from most basic house hold application to most complex structures and machineries. There are more than 3500 different types of steel grades based on different physical, chemical \& environmental properties. Approx. $75 \%$ of modern steels been developed in past 20 years i.e. the cars made today are made of steel that is 35\% lighter than past yet more stronger. A variety of microstructures and properties can be achieved in steel by adjusting the chemical composition and conditions used to cool the steel from the austenizing temperature to room temperature. The process of heating steel to predetermined temperature, holding at this temperature for sufficient time followed by cooling at predetermined cooling rate in different cooling media or quenching media to achieve the desire microstructures and properties in steel is usually known as heat treatment.

Though prodigious advances have been made recently in steel heat treating practice and in the understanding of the transformations in steel, the process of hardening steel by quenching it in a liquid bath has been in use for 100 of years. The most common used quenching media from years have been water and mineral oil. Though today if oil and water were compared for the same application, attention would probably be focused on cracking and warpage during quenching. Any modern text on steel heat treating lists many quenchants in addition to water and oil. Each quenchant has certain characteristics which make it most suitable for specific applications. (Eckel, 1951)

The commonly used quenchants are water, oil, brine, and synthetic solutions. Water though abundant and low cost has the drawback of inducing crack or distortion on the quenched component due to its high cooling rate and oil has the problem of not inducing enough hardness. Polymer quenchant though can provide severity between those of water and oil has the problem of varying concentration during the quenching process and it is also more expensive. Brine produces more quenching severity than water; but it also has a problem of corrosive attack on the components and the equipment used for the quenching. (Eckel, 1951) (Higgins, 1995) (Hassan, Agboola, Aigbodion, \& Williams, 2011)

The function of a quenching medium is to enhance heattransfer rate extraction from the hot-metal during the cooling 


\section{International Journal of Engineering Applied Sciences and Technology, 2020 Vol. 4, Issue 10, ISSN No. 2455-2143, Pages 253-259 \\ Published Online February 2020 in IJEAST (http://www.ijeast.com)}

process and to produce the desired metallurgical transformation. The quenching media selected depends on the quenching severity required to obtain the desired properties while at the same time providing optimal residual stresses and distortion control. (Prabhu K. N., 2007) Mineral oils are mostly used in as oil quenchants in industries due to its excellent cooling capacity. However, it is relatively expensive, toxic and non-biodegradable. However, biodegradability of these petroleum derived products is problem, because in environment some chemical compounds blockaded the basic cycle of vital elements such as carbon. (Farah, 1999)

Consequently the search for alternative quenchants is fundamental to avoid environment pollution. The quenchants based on vegetable oils, when compared with mineral oils , have some advantages such as renewables resources, inherent biodegradability, lower toxicological \& bio toxicological risk, higher flash \& boiling points. However there are some disadvantages such as oxidative instability, poor low temp characteristics \& narrow viscosity range. Also, the need to be energy independent and increasing cost of mineral products also lead to drive the interest of finding alternative or hybrid quenching media. (Farah, 1999)

Vegetable and animal oils have been used as quenchants for steel for hundreds of years, if not longer, until they were generally replaced by petroleum oil quenchants in the early 1900s. (Otero, 2011) Vegetable oils - as all kind of oils and fats - are triglycerides with a distribution of saturated, monounsaturated and polyunsaturated fatty acids. These carboxylic acids contain typically a large amount of carbon atoms. In case of vegetable oils the main acids are palmitic acid, stearic acid (saturated ones) and oleic, linoleic, linoleic acids (monounsaturated and polyunsaturated ones) the reasons why these could be a potentially alternative quenching media instead of mineral ones are the Leiden frost-effect is missing in case of many type of these, regeneratory, and eco-friendly. (Higgins, 1995) (Gábor Kerekes, 2016)

Among various quenching media, polymer solutions have recently become widespread. As a rule, the cooling ability of these media lies between that of water and oil. (Bannykh, 1981) The plain carbon steels (C \%-0.05\% to $2 \%$ ) also known as carbon steel is group of 3 alloys; low carbon (mild) steels $(\mathrm{C} \%$ $0.05 \%$ to $0.3 \%$ ); medium carbon steel (C \%- $0.3 \%$ to $0.6 \%$ ) and high carbon steels (C \%- 0.6 to $1 \%$ ) (contributors, 2020). These are alloys of iron and carbon with minor amounts of silicon, manganese etc. We have used medium carbon steel (EN-9) to study effect of different quenching media. The medium carbon steel find its application in structural works, tools manufacturing, automobile industries etc.; due to its carbon percentage in range of $0.3 \%$ to $0.6 \%$ and it is having good mechanical properties, that can be enhanced by heat treatment.

The heat treatment in steel is performed to control the transformation of austenite to prevent ferrite and pearlite formation at high temperatures and to allow the formation of bainite and martensite at low temperature. Typically, for carbon and alloy steels, martensite is the desired microstructure due to its relatively high strength and hardness. Quenching is necessary to increase the mechanical properties of steel, this process is often accompanied by high thermal stresses and transformational stresses which may lead to high residual stresses and distortions and possibly cracking. Therefore, it is desirable to develop quenching processes that maximize the material properties while minimizing the residual stresses and distortions. (C.Civera, et al., 2014)

Many research have put effort to know the effect of vegetable oil and other alternative quenching media on medium carbon steel and other materials. Some researchers Performed quenching experiment on AISI 4140 and AISI H13 steel by using 6 different vegetable oil (soybean oil) blends as quenching media to study residual stress and dimensional changes. Results were compared with 2 different commercial mineral oil quenchants; the residual stresses obtained on the specimens quenched in vegetable oils and petroleum-based oils were comparable and no considerable difference found in terms of distortion and residual stress. (Eckel, 1951) (C.Civera, et al., 2014)

Some researchers performed experiment to find hardening characteristics of medium carbon steel and ductile cast iron using Neem oil, SAE engine oil (mineral oil) and water as quenchants (to find out effectiveness of quenchants). The microstructure and mechanical properties of quenched samples were used to assess the quenching severity of quenchants. Neem oil quench samples had hardness value less than that of water but higher hardness value than that of SAE40 engine oil. The microstructure of the samples quenched in the Neem oil revealed the formation of martensite. Neem oil samples had higher impact energy values than water. Hence, Neem oil can be used where cooling severity less than that of water but greater than SAE 40 engine oil is required for hardening of plain carbon steels and ductile cast iron. (Hassan, Agboola, Aigbodion, \& Williams, 2011)

The effect of polyethylene glycol $[\mathrm{H}(\mathrm{OCH} 2 \mathrm{CH} 2) \mathrm{nOH}]$ as quenchant was studied with a view to investigate the mechanical properties and microstructural evaluation of steel by some researchers; (I. M. Momoh, 2015) The hardness increases with decrease in the polymer concentration, The impact energy displays an inverse relationship with the polymer concentration, ultimate tensile strength also decreases as the polymer in the mixture increases, micrographs justify the reason for the increment recorded in the mechanical properties as it displayed high proportion of martensitic phase. (Eckel, 1951) (I. M. Momoh, 2015)

One researcher (Gábor Kerekes, 2016) presented overview of possibility of use bio-oils as quenchant. The results showed that bio-oils can be a real alternatives of mineral oils in a given case of course. The thermo-kinetic parameters of sunflower, soybean and corn oils were same or better than the investigated mineral quenching oil. (Gábor Kerekes, 2016)

Due to demerits of water and oil we have tried to study the effect of various quenching media like brine (37\% salt + water), vegetable oil (cotton seed oil), water, oil-in-water emulsion 


\section{International Journal of Engineering Applied Sciences and Technology, 2020 \\ Vol. 4, Issue 10, ISSN No. 2455-2143, Pages 253-259 \\ Published Online February 2020 in IJEAST (http://www.ijeast.com)}

lubricant (rolling mill coolant) \& hybrid polymer quenchant (polyethylene glycol + salt + water) to observe effect on En-9 steel (medium carbon steel) and make a comparative study to know the severity of these quenches by mechanical \& metallographic testing.

\section{EXPERIMENTAL PROCEDURE}

The raw material used in this investigation include EN 9 grade steel rod in hot rolled condition. The chemistry of the Sample is given below in table 1. The chemistry of sample EN 9 has $\mathrm{C}$

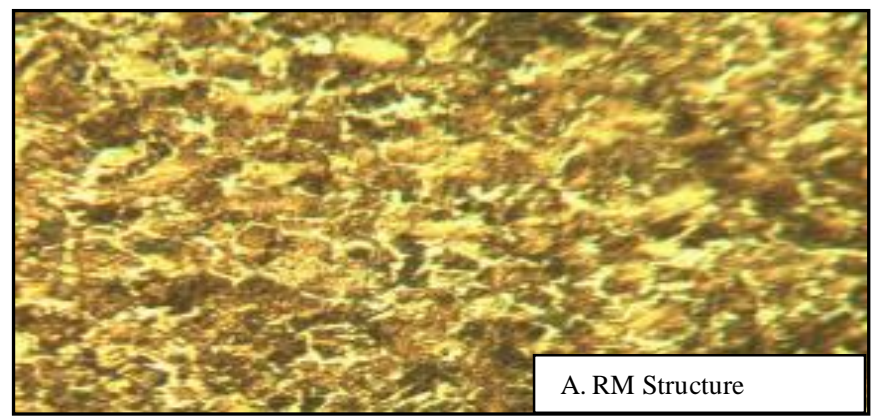

Fig. 1. Raw material structure of EN 09 steel (hot rolled condition)

$\% 0.54$ hence the TTT diagram of medium carbon steel was used as a reference to assess behaviour of different quenching media on transformation product of EN 9 during this study. (ASM International. Handbook Committee, 1991)

Table 1. Chemical compositions of Sample (EN 9).

\begin{tabular}{|l|l|l|l|}
\hline $\mathrm{C}-\mathbf{0 . 5 4 \%}$ & $\mathrm{S}-\mathbf{0 . 0 1 4} \%$ & $\mathrm{Cr}-\mathbf{0 . 0 4 2} \%$ & $\mathrm{Mo}-\mathbf{0 . 0 0 0 3}$ \\
\hline $\mathrm{Mn}-\mathbf{0 . 7 3 \%}$ & $\mathrm{P}-\mathbf{0 . 0 1 5} \%$ & $\mathrm{Ni}-\mathbf{0 . 0 0 5 \%}$ & $\mathrm{V}-\mathbf{0 . 0 0 2}$ \\
\hline $\mathrm{Si}-\mathbf{0 . 2 1 4} \%$ & $\mathrm{Al}-\mathbf{0 . 0 2 5 \%}$ & $\mathrm{Cu}-\mathbf{0 . 0 0 3} \%$ & $\mathrm{Fe}-\mathbf{9 8 . 3 6 \%}$ \\
\hline
\end{tabular}

Along, water and vegetable oil (cotton seed oil). The industrial oil, brine solution ( $34 \%$ salt + water), oil-in-water emulsion lubricant (rolling mill coolant), and hybrid polymer quenchant (polyethylene glycol + salt + water) was used as a quenching media for the investigation. Each media has quenching volume of approx. 5 litre. All the experiment was performed in electrically heated muffle furnace where $\mathrm{N}_{2}$ is used as inert gas to create protective atmosphere and to avoid decarburization of steel sample. The physical dimensions of each sample was fixed as $300 \mathrm{~mm}$ in length and $14 \mathrm{~mm}$ in diameter. The samples were collected from hot rolled wire coil which was manufactured from continuous casted bloom. After sampling from coil the samples were processed for residual stress removing treatment that is called pre-heat treatment (stress relieving). Stress relieving cycle and other parameter is mention in below fig 2 . The properties after stress relieving is presented in Table 2. The microstructure of stress relieving sample is presented in fig.3.

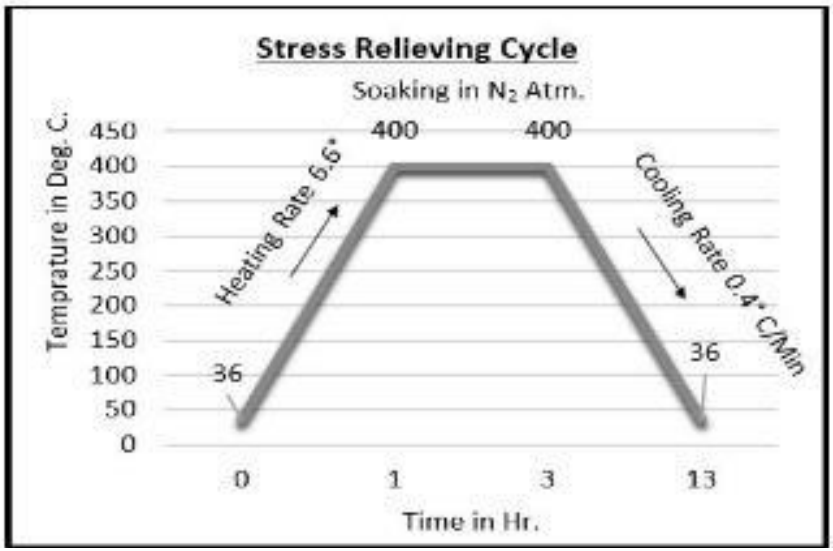

Fig. 2. Heat - Treatment Cycle for Stress Relieving Treatment with operational Parameters.

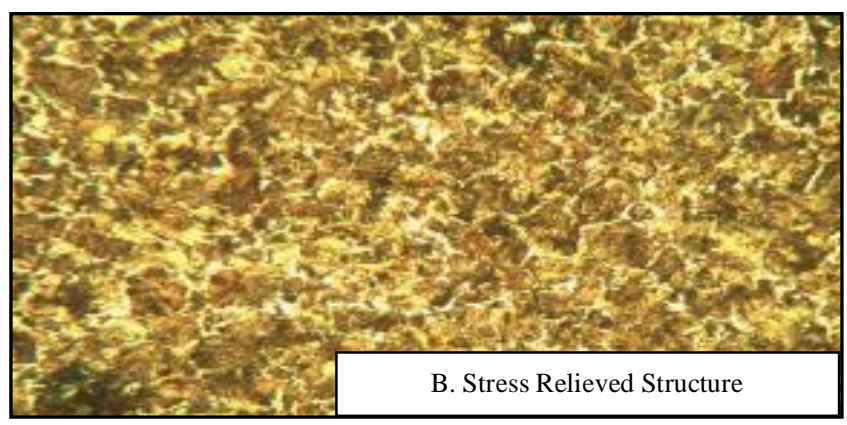

Fig. 3. Structure after stress relieving process (Before Hardening)

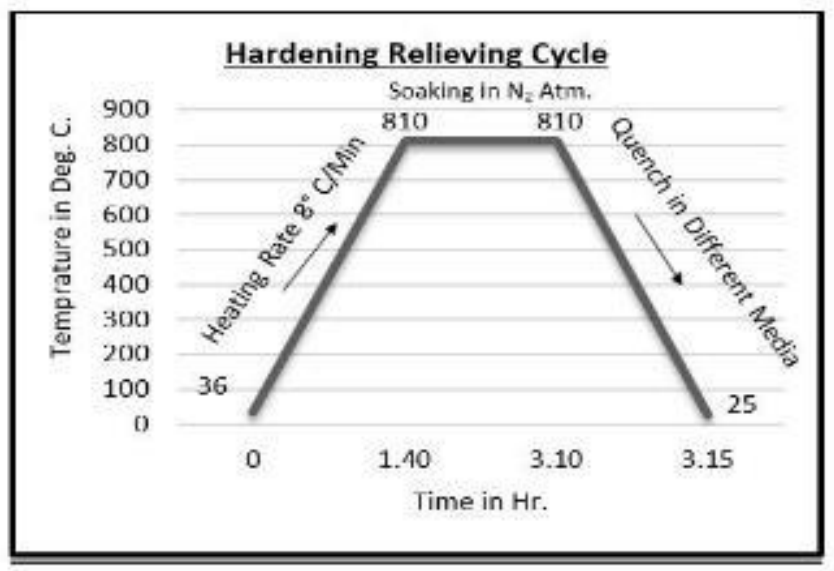

Fig. 4. Heat - Treatment Cycle for Hardening Treatment with operational Parameters. 


\section{International Journal of Engineering Applied Sciences and Technology, 2020 Vol. 4, Issue 10, ISSN No. 2455-2143, Pages 253-259 \\ Published Online February 2020 in IJEAST (http://www.ijeast.com)}

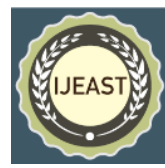

Heating and cooling rates for hardening mentioned in the following heat treatment cycle presented in fig. 4. The Heating rate was decided as per standard. (ASM International. Handbook Committee, 1991). After Stress Relieving cycle the samples were treated under Hardening Treatment.

Table 2. Mechanical properties of stress relieved sample (EN 9).

\begin{tabular}{|l|c|c|c|}
\hline $\begin{array}{c}\text { Hardness } \\
(\text { HRC })\end{array}$ & $\begin{array}{c}\text { Tensile Strength } \\
(\mathrm{kg} / \mathrm{mm} 2)\end{array}$ & $\begin{array}{c}\text { YIELD STREGTH } \\
(\mathrm{kg} / \mathrm{mm} 2)\end{array}$ & $\begin{array}{c}\text { \% ELONGATION } \\
\text { (50 mm GL })\end{array}$ \\
\hline $12-12-11$ & $\mathbf{6 5 . 0 5}$ & 46.87 & $27 \%$ \\
\hline
\end{tabular}

Six heat treatment cycles were performed individually during experiment. Water, Vegetable oil (cottonseed oil), industrial oil, brine (37\% Nacl + water), $2.4 \%$ oil-in-water emulsion lubricant (rolling mill coolant), hybrid polymer quenchant (polyethylene glycol + salt + water) were used as a quenching agent respectively. Heating rate and soaking time was constant for each treatment. The heating rate was $8^{\circ} \mathrm{C} / \mathrm{min}$ and soaking time was $1 \mathrm{hr} .30 \mathrm{~min}$ (soaking time was decided on the basis of cross section area of the sample). This parameter was decided from standard. (ASM International. Handbook Committee, 1991) Pre-heat treatment (stress relieving) and hardening treatment was carried out under $\mathrm{N}_{2}$ atmosphere to prevent decarburization of steel. After completion of experiment the mechanical and metallographic characterization carried out. The hardness test was performed in Vickers hardness scale for more accuracy as well as in HRC scale. The metallography analysis was performed with metallurgical microscope and tensile test with universal testing machine (80 MT capacity). The characterization was performed on as-quench condition of samples (hardened condition).

\section{RESULTS \& DISCUSSION}

Each quenchants having different properties and different quenching severity that make it difficult to choose the adequate quenchant for quenching purpose also the cooling ability of quenchant vary from one to another. There are various parameters to choose quenching media i.e. Availability, Cost, toxicity, reusability, maintainability, chemical properties, thermal properties etc...

It is difficult to characterize how physical \& chemical properties of quenchants might affect their quenching performance. (Adebiyi, 2015) We have choose the quenching media accordingly keeping in mind of above parameter to make a good competitive study among different quenchants.

Table 3. Tentative Volume of different phases after quenching in respective media mention in below table.

\begin{tabular}{|c|c|c|c|c|c|}
\hline Media / Condition & Ferrite & Pearlite & Bainite & Martensite & RA \\
\hline RM & 32.82 & 67.17 & - & - & - \\
\hline Stress Relieve & 32.82 & 67.17 & - & - & - \\
\hline Water & - & 8 & $7-11$ & 68 & $10-12$ \\
\hline Brine & - & 5 & 5 & 85 & $3-7$ \\
\hline Industrial Oil & $2-3$ & $1-3$ & 82 & 7 & $2-4$ \\
\hline Vegetable Oil & 2 & 2 & $79-85$ & 9 & $2-3$ \\
\hline $\begin{array}{c}\text { Rolling Mill } \\
\text { coolant }\end{array}$ & - & - & $1-2$ & 88 & 8 \\
\hline $\begin{array}{c}\text { Hybrid Polymer } \\
\text { solution }\end{array}$ & $2-3$ & $12-14$ & $20-22$ & 61 & $0-2$ \\
\hline
\end{tabular}

To determine or evaluate the structure of hardened steel sample, these examination carried out under optical metallurgical microscope at various magnification. The samples for metallography were cut along cross section and was helpful to observed the structure surface to center and these samples were polish, etched with $2 \%$ Nital solution (2\% nitric acid + $98 \%$ methanol) and analyzed using the metallurgical microscope.

After hardening treatment, samples were quenched in six different quenching media. To evaluate the quenching effectiveness, metallographic analysis of the received and quenched specimen were carried out on 200X magnification and the microstructure evaluation cum phase amount are mention in table 3. Raw material structure indicates presence of grain boundary phases where stress relived microstructure indicates reduction in grain boundary phases which is responsible for changes in the mechanical properties of EN 9 steel. The metallographic structure of $2.4 \%$ oil in water emulsion quenching media offers the high amount of martensite, retained austenite and uniformly distributed carbide as presented in Fig.5. It is due to high quenching severity of the bath. The high severity of oil-in-water emulsion is due to $97.6 \%$ of water, this media

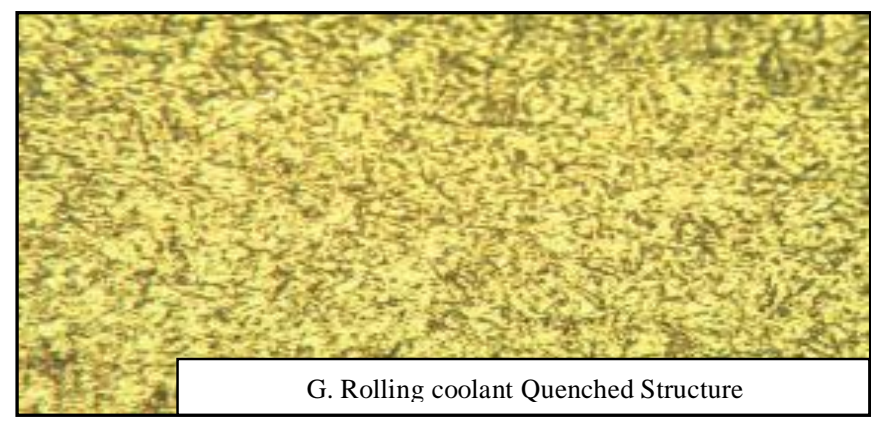

Fig.5. Structure Developed by Rolling mill coolant Quenching.

have less severity to distortion and quench crack formation as compared to water due to $2.4 \%$ addition of mineral oil that reduce the vapor blanket stage. The microstructure also offers good corrosion resistance properties compared to other quenching media. It is also anticorrosive, non-toxic \& easily available.

We got martensitic structure \& retained austenite in water quenching as per fig. 6 but the amount of martensite is still high in oil-in-water emulsion quenchant \& oxide scale was observed in water quenching while in oil-in-water quenchant no oxidation observed. There are also chances of quench crack formation \& distortion in complex parts in case of water quenching so $2.4 \%$

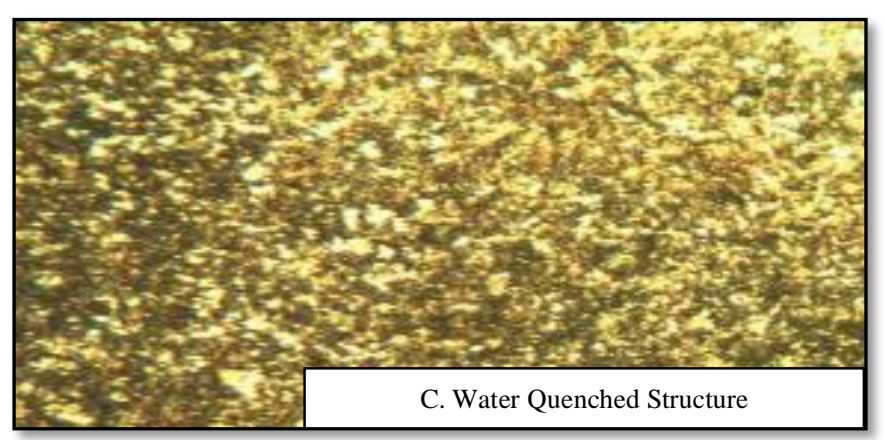

Fig. 6. Structure Developed by Water Quenching 


\section{International Journal of Engineering Applied Sciences and Technology, 2020 Vol. 4, Issue 10, ISSN No. 2455-2143, Pages 253-259 \\ Published Online February 2020 in IJEAST (http://www.ijeast.com)}

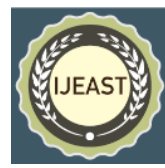

oil-in-water could be good replacement in case of achieving high hardness with less chances of distortion \& quench cracks.

The brine solution was prepared by making solution of $37 \%$ salt in water and heat treatment cycle was followed as shown in Fig.2, very few amount of retained austenite, lath martensite and ferrite is observed as shown in Fig.7. The morphology of martensite was observed as 'lath martensite' this increase the

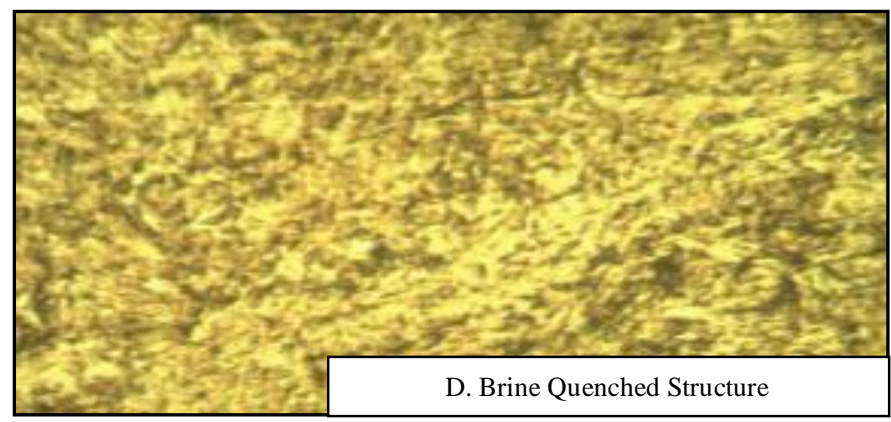

Fig. 7. Structure Developed by Brine Quenching.

hardness and tensile strength of steel. The increasing concentration of salt in water increase the sphericity of grain size $\&$ favor grain growth, grain size distribution. (Adebiyi, 2015) When a piece of hot metal is quenched in a brine solution, deposition of minute salt crystals and violent fragmentation of this salt layer occurs on the hot metal surface. This creates turbulence at the metal/quenchant interface, which destroys the vapor phase, resulting in a very high cooling rate and uniform rewetting. (Prabhu G. R., 2015)

The sample quenched in industrial oil showed presence of martensite, lower bainite and small amount of carbide $\&$ retain austenite Fig. 8 while the sample quenched in cotton seed oil showed nearly same microstructure as similar to industrial oil quenching but the small cluster \& size of martensite is observed in cotton seed oil as compared to industrial oil. So we can assess from the observations that the quenching severity of cotton seed oil is quite similar to industrial oil.

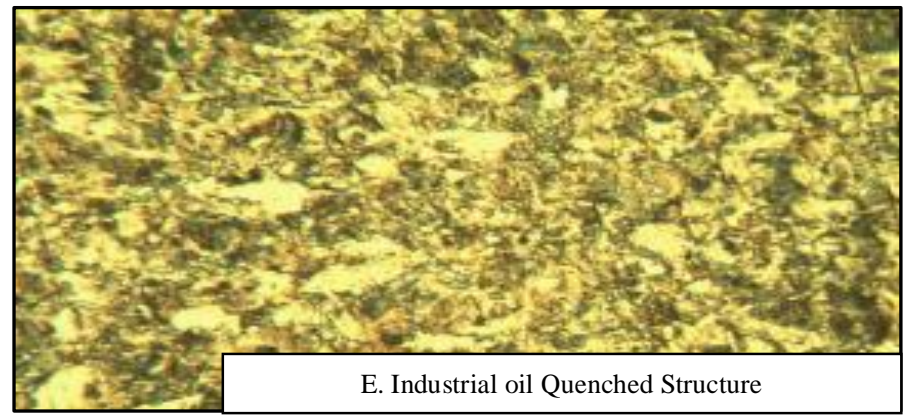

Fig.8. Structure Developed by Industrial Oil - Quenching.

We can use cotton seed oil in place of industrial oil. The use of vegetarian oil show no distortion or oxidation of sample. The industrial oil is used widely due to less severity to distortion, internal stress generation \& oxidation but the fumes and toxicity of industrial oil and its non-bio-degradability is problem for industries and environment. So, vegetable oil can be suitable quenching media due to its bio-degradability and comparative behavior as industrial oil. The microstructure if vegetable oil quenched sample is shown in fig.9.

The sample quenched in hybrid polymer quenching media showed presence of martensite, retained austenite and small

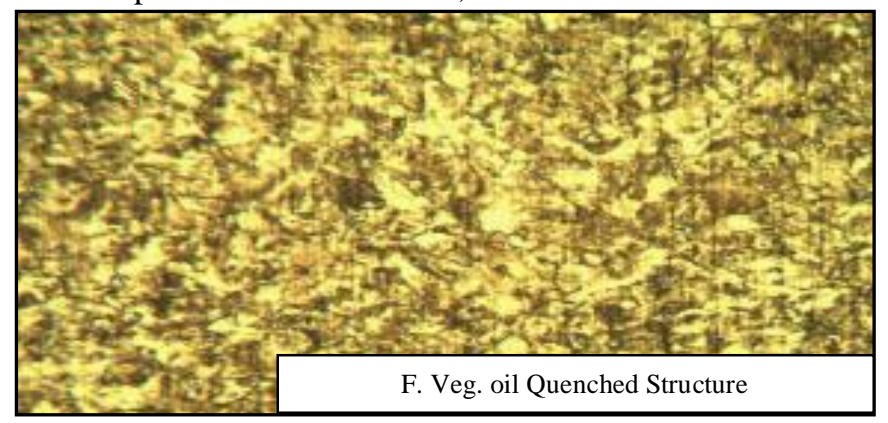

Fig.9. Structure Developed by Vegetable oil Quenching.

amount of ferrite Fig. 10 the clusters of martensite is observed in microstructure on matrix of ferrite. The hybrid polymer quenching media was made by synthesis of $20 \%$ polyethylene glycol-400, $10 \% \mathrm{NaCl} \&$ rest water. The benefit of polymer and salt make hybrid quenching media a new area of interest for researchers. The presence of ferrite $\&$ martensite add in adequate ductility with hardness. During polymer quenching, a polymerenriched film is` formed around the hot metal, which stabilizes

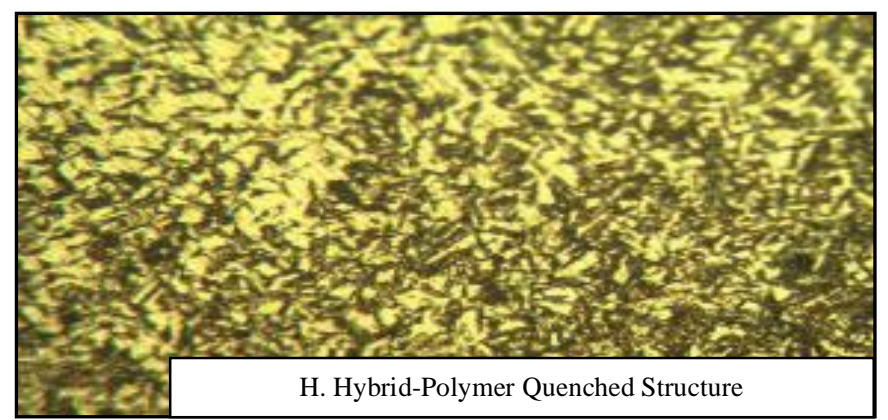

Fig.10. Structure Developed by Hybrid - polymer Quenching. the vapor blanket.

As the temperature of the hot surface decreases approximately to the rewetting temperature the vapor blanket explosively ruptures, resulting in a pseudo-nucleate boiling process. Polymer quenching results in a longer vapor film stage and uniform cooling. (Prabhu K. N., 2007) The combined effect of salt and polymer solution additions on a cooling mechanism during quenching control the distortion $\&$ residual stress in steel.

The tensile test carried out with $14 \mathrm{~mm}$ dia. and hardness was determined with 'Vickers' and 'Rockwell scale'. One important reasons for determining quenching intensity of various quenchants under production conditions are the multiple quenchants that are currently available such as: Different mineral oils, vegetable and synthetic oils; polymer quenchants; salt bath media; pressurized circulating gases etc. 
Hardness \& Tensile test were performed on all specimens to evaluate the mechanical properties of the samples. All data of mechanical testing is shown in table.3.

The sample quenched in water showed hardness of $410 \mathrm{HV}$ near surface and $394 \mathrm{HV}$ near core due to high quenching severity of water, the tensile strength of $138.70 \mathrm{~kg} / \mathrm{mm} 2,2.7 \%$ elongation was observed. So we can assess high hardness with low ductility in water quenched steel. The sample quenched in Brine solution show hardness of $420 \mathrm{HV}$ near surface and 410 $\mathrm{HV}$ near core with tensile strength $150 \mathrm{~kg} / \mathrm{mm} 2,2.3 \%$ elongation was observed due to very high cooling rate and high amount of martensitic structure the hardenability and hardness observed better than water quenching. The sample quenched in $2.4 \%$ oil-in-water emulsion quenchant show hardness of 432 HV near surface and 432 near core with tensile strength of 139.8 $\mathrm{kg} / \mathrm{mm} 2,3 \%$ elongation was observed due to highest amount of martensite and high cooling rate among all quenchants. Also, good ductility can be assessed from tensile strength and \% elongation as compared to water \& brine solution. The sample quenched in industrial oil showed hardness of $345 \mathrm{HV}$ near surface and $338 \mathrm{HV}$ near core with tensile strength of 110 $\mathrm{kg} / \mathrm{mm} 2,6 \%$ elongation was observed due to presence of lower bainite, martensite and retained austenite. The adequate hardness and toughness can be assessed from tensile strength, \% elongation \& hardness.

The sample quenched in cotton seed oil showed hardness of $358 \mathrm{HV}$ near surface and $355 \mathrm{HV}$ near core with tensile strength of $118 \mathrm{~kg} / \mathrm{mm} 2,6 \%$ elongation which is quite good compared to industrial oil as nearly comparable microstructure was observed. The sample quenched in hybrid polymer solution showed hardness of $380 \mathrm{HV}$ near surface and $376 \mathrm{HV}$ near core with tensile strength of $121 \mathrm{~kg} / \mathrm{mm} 2,4 \%$ elongation due to presence of martensitic structure embedded in ferrite matrix. The good combination of ductility and hardness can be assessed from mechanical properties and results are quite comparable to industrial oil and cotton seed oil with adequate hardness and tensile strength there is no need of further heat treatment like normalizing or tempering as in water quenched steels.

Evaluation of mechanical properties of as quenched structure give result mention in table no. 4 in terms of hardness, tensile strength, yield strength, $\%$ of elongation and $\%$ of reduction. The maximum hardness achieved in mill coolant quenched sample and lowest in industrial oil.

Table 4. Results of Various samples which was quenched in difference media.

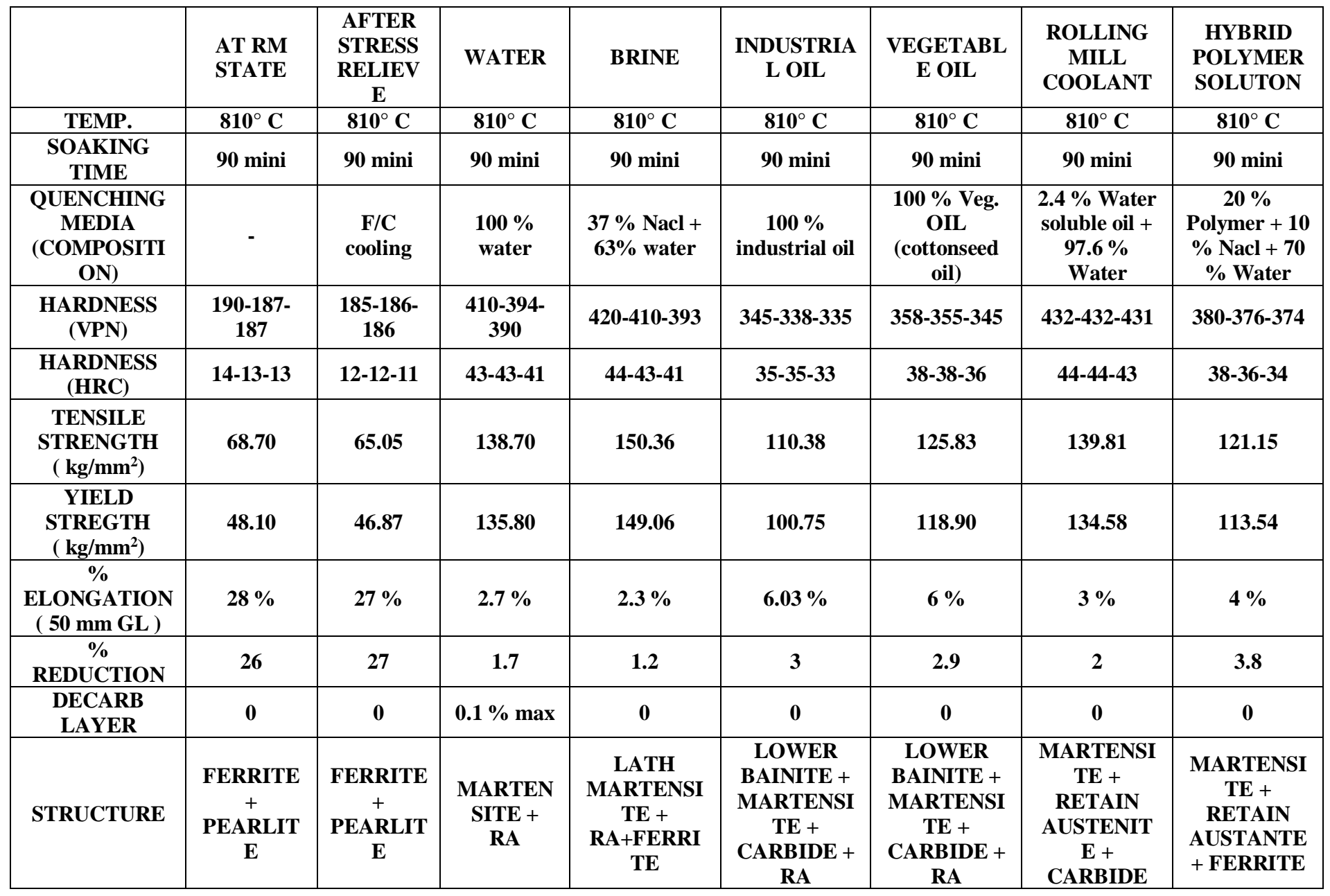




\section{International Journal of Engineering Applied Sciences and Technology, 2020 Vol. 4, Issue 10, ISSN No. 2455-2143, Pages 253-259 \\ Published Online February 2020 in IJEAST (http://www.ijeast.com)}

\section{CONCLUSION}

From the above research activities following conclusion can be derived;

1. Highest hardness (44 HRC) obtained by using brine \& rolling mill coolant as quenching media.

2. Highest tensile strength is achieved by using brine as a quenching media with a value of $150 \mathrm{~kg} / \mathrm{mm}^{2}$

3 . The structure developed by rolling mill coolant showed uniform structure along with less retained austenite from that good corrosion properties can be assessed.

\section{ACKNOWLEDGEMENT}

After an intensive period of 8 months, today is the day writing this note of thanks in finishing touch of our research. We would like to reflect on people who have supported $\&$ helped us so much throughout this period.

Our sincere thanks goes to Dr. Vandana J. Rao for helping us in investigation part. She has inspired us to become independent researchers \& helped us to realize the power of intelligence, over knowledge, simple fundamental logic behind bigger issues through stories. During our tenure, she contributed to a rewarding graduate experience our work, engaging us in new ideas \& demanding a high quality of work in all our endeavors. Finally, we are grateful to our parents, who provided a carefree environment for us so that we can concentrate on our research, we deeply thank our parents for their unconditional trust, timely encouragement \& endless patience. It was their love that raised us up again when we got worried.

\section{REFERENCES}

[1] ASM International. Handbook Committee (1991) ASM handbook. Vol. 4, Heat treating Materials Park, OHASM International, 1991.

[2] Contributors, W. (2020, 02 10). Carbon Steel. (T.F. Wikipedia, Producer) Retrieved from Wikipedia, The FreeEncyclopedia:https://en.wikipedia.org/w/index.p hp?title=Carbon_steel\&oldid=940116678

[3] Farah, A.a. (1999, 01). Caster Oil: Studies for Heat Treatment Applications. 251-254

[4] Prabhu, G.R. (2015). Comparative Study of Wetting and Cooling Performance of Polymer-Salt Hybrid Quenching Medium with Conventional Quenching Media.

[5] Zupan,J. \& (2020). Cooling Characteristics of the Water Based Nano fluids in Quenching. International Conference on materials, tribology, recycling. MATRIB 2011.
[6] Prabhu, K.N. (2007). Determination of Wetting Behavior, Spread Activation Energy, and Quench Severity of Bioquenchants. 38(4).

[7] Adebiyi, K.M. (2015), Effect of Brine Solution on Grain Size Formations in AISI 1080 Low Carbon Steel. 12(3)

[8] I. M. Momoh, B.J. (2015). Effects of Polyethylene Glycol on the Mechanical Properties of Medium Carbon Low Alloy Steel. 12(2)

[9] Higgins, R. (1995). Engineering Metallurgy. $\ln$ R. Higgins, Engineering Metallurgy (pp. 218-257, 285354). UK: Edward Arnold UK.

[10]Eckel, E.J (1951), Evaluation of The Hardening Power of Quenching Media for Steel (Vol. 48), (E.J. Eckel, Ed.) University of ILLINOIS.

[11] C.Civera, B.Rivolta, Simencio-Otero, R.L Lucio, J.G, G.E. Canale, L.C (2014). Vegetable Oils as Quenchants for Steels: Residual Stresses and Dimensional Changes. Materials Performance and Characterization.

[12] Hassan, S., Agboola, J., Aigbodion, V., \& Williams, E. (2011). Hardening Characteristics of Plain Carbon Steel and Ductile Cast Iron Using Neem Oil as Quenchant. Journal of Minerals \& Materials Characterization \& Engineering, 10(2), 161-172.

[13] Rajan T.V., C.P. (1988). Heat Treatment, Principles and Techniques. In Heat treatment, Principles and Techniques. (pp. 143-150, 236-380). new delhi: prentice-hall of New Delhi-India.

[14] Bannykh, A.V. (1981). New Quenching Media Based on Water-Soluble Polymers. 2.

[15] Gabor Kerekes, M.K. (2016). Possibility of Use Bio Oils as Quenchant. Hungary; microCAD International Multidisciplinary Scientific Conference. International Multidisciplinary Scientific Conference

[16] Otero, R.L. (2011). Use of Vegetable Oils and Animal Oils as Steel Quenchants: A Historical Review-18502010. 9(1). 